\title{
Marijuana: Real medicine or reefer madness?
}

Despite voters' approval in two states of special initiatives that would allow the medical uses of marijuana, the administration of US President Bill Clinton has warned doctors that they face criminal prosecution and other penalties if they prescribe the drug for their patients. Among the penalties would be the loss of their authorization to prescribe controlled substances, including common pain killers. "Our health care professionals need to understand that federal law has not changed," said Health and Human Services Secretary Donna Shalala. "It continues to be illegal in the United States to prescribe marijuana." Nevertheless, the Clinton Administration is planning to fund a study on the health effects of marijuana and any possible medical benefits, and the director of drug policy for the White House has asked the Institute of Medicine to assess what is scientifically known and unknown about the drug. Administration officials had considered filing a lawsuit against the two marijuana initiatives on the grounds they conflicted with federal drug laws, but lawyers in the Justice Department backed away after concluding they would probably not prevail in court.

Last December, voters in California and Arizona approved referenda that would sanction the medical use of marijuana, which is classified as an illegal drug in the United States. Such medical uses include relieving the nausea and appetite loss that is often a side effect of cancer and AIDS therapies, easing muscle spasms associated with spinal cord injuries or multiple sclerosis and decreasing eye pressure in individuals with glaucoma.

Although US physicians are licensed to practice by the individual states where they are located, they also must receive authorization from the US Drug Enforcement Administration - the agency that regulates narcotics - to prescribe controlled substances. If they lose such authorization, their practices would be all but destroyed. Federal prosecutors said in letters sent to medical groups and state agencies that they "unequivocally will seek to revoke the DEA registrations of physicians who recommend or prescribe Schedule I controlled substances," such as marijuana. Health officials also said these doctors could be excluded from the
Medicare and Medicaid programs, the government-funded health assistance programs for the elderly and the poor. Moreover, Attorney-General Janet Reno said federal prosecutors will bring a few criminal cases against doctors who deal in a "high volume" of marijuana or give the narcotic to minors.

The White House director of drug control policy, retired General Barry R. McCaffrey, dismissed the notion that the action of the two states in sanctioning certain uses of marijuana was a medical proposition. "This is the legalization of

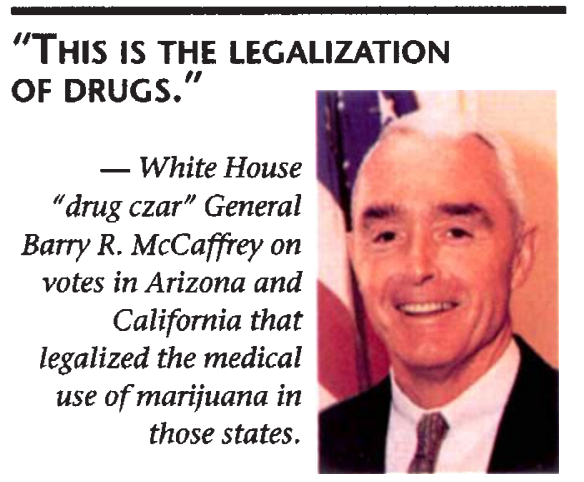

drugs," he said. McCaffrey and other officials said they were most concerned that teenagers would be led to believe that marijuana is harmless.

Advocates of the medical marijuana initiatives have accused the government of turning the war on drugs into a "war on doctors." And the American Civil Liberties Union said the Clinton administration's response "shows the extent to which our government's drug policies have spun out of control and are now poised to go off the deep end."

California Proposition 215, which was favored by 56 percent of the state's voters, decriminalizes the possession of marijuana by patients and caregivers if its use has been recommended by a physician. Arizona's Proposition 200 goes one step further by allowing ill persons to use stronger narcotics, including heroin or LSD, if approved by two licensed physicians.

There has been a long debate within the medical community about the value of marijuana as a medical treatment. While some physicians favor it, others do not believe it is an effective therapeutic tool. The California Medical Association, which opposed the initiative, has advised its 35,000 members not to recommend marijuana to patients. But organizations within the state were divided: the San Francisco Medical Society favored it, for instance, and the Los Angeles Medical Society was opposed, arguing that federal laws against marijuana needed to be changed before marijuana could be acceptable as a medical tool. A 1991 Harvard Universitysponsored study found that 40 percent of US cancer specialists surveyed recommended that their patients smoke marijuana to relieve chemotherapy-induced nausea, and 48 percent said that they would prescribe it in certain cases, if the drug were legal. But some doctors believe that smoking marijuana, just like smoking cigarettes, can cause lung damage and oppose its use for those reasons.

Compounds are already available that are related to the active chemical constituent of marijuana and that can be taken orally. One that is currently available by prescription is dronabinol (Marinol), a $\Delta^{9}$-tetrahydrocannabinol (THC).However, dronabinol is not well absorbed by some patients and can cause a "high" similar to that of smoking marijuana cigarettes, which may be unpleasant for those inexperienced in marijuana use. Furthermore, some medical experts believe these substances, although legal, are not as effective as other drugs or drug combinations in controlling nausea and vomiting.

A recent report released by federal health officials said that the use of illegal drugs by young people in the United States - especially marijuana - increased last year, continuing a trend that began in 1991. Although marijuana use has not approached the peak levels of the 1970s, it has tripled among 12- to 13-year-olds since 1991; more than doubled among 10th graders since 1992; and increased by nearly two-thirds among high school seniors since 1992, according to the annual Monitoring the Future Study, funded by the National Institute on Drug Abuse and conducted by the University of Michigan's Institute for Social Research. The survey has been conducted annually for 22 years, and is regarded as a significant barometer of drug use trends among young people in the United States.

MARLENe Cimons Washington, $D C$ 